\title{
The dandelion evolution outreach program: learning through inquiry-based community engagement
}

\author{
Shoshanah R Jacobs ${ }^{1 *}$, Susan Bender ${ }^{2}$ and Andrew McAdam ${ }^{1}$
}

\begin{abstract}
Background: Science outreach programs have positive effects on students in both elementary and high school, but are often developed as internships, thus limiting access and requiring significant financial investment. Several larger scale evolution-themed outreach programs have been developed in the United States where academic institutions are addressing a specific need to actively promote science-thinking in direct opposition to other ways. This context is unfamiliar in other countries.

Results: Here we present a pilot implementation of the Dandelion Evolution Outreach Program designed to provide an inquiry-based learning opportunity in evolution for grade 11 high school students in Ontario, Canada. This program is flexible with respect to time commitment, low cost, is applicable throughout North America and many other regions of the world, and is learner-centered through active learning with both simulation and inquiry-based activities. We found that students were engaged with our lesson plan including both the simulation and inquiry-based activities. Results of our post-assessment suggested that students were able to formulate appropriate predictions relevant to the concepts of natural selection. The scalability of this program will be demonstrated further as more schools become involved in future offerings.
\end{abstract}

Conclusions: The Dandelion Evolution Outreach Program is an effective means of engaging secondary school students in active, inquiry-based learning that does not restrict access.

Keywords: Evolution outreach; Inquiry-based learning; Community engaged research

\section{Background}

The American Association for the Advancement of Science (2001) encourages teachers to offer their students the ability to explore nature from a scientist's perspective (as cited in Markowitz 2004) and promotes students' participation in inquiry-based learning; an approach that is practiced frequently in post-secondary educational institutions. In Ontario, Canada, the province's secondary school education goals include: creating opportunities for handson learning and recognising learning opportunities that are available from outside of the school (The Ministry of Education 2008).

Motivated by the perception that high school teachers experience difficulty in keeping up to date with science

\footnotetext{
* Correspondence: sjacob04@uoguelph.ca

'Department of Integrative Biology, University of Guelph, N1G 2 W1 Guelph, ON, Canada

Full list of author information is available at the end of the article
}

innovation and discovery, some universities have launched outreach programs aimed at improving science education for the participating students and leading change in the teaching of science curriculum (i.e. Biomedical: Gibson and Chase 2002; Helm et al. 1999; Markowitz 2004; McKendall et al. 2000; Waksman 2003). Some programs are designed to direct students into future vocations (i.e. Louie et al. 2011; Merton 2011,) or into broader directions, such as the STEM fields (Science, Technology, Engineering and Mathematics, i.e. Kimbrough 1995). Generally, outreach programs that occur on university campuses have been shown to have positive effects on student comprehension and inquiry abilities (Bell et al. 2003; Kimbrough 1995). For example, Stanford University's High School Internship program offered through the School of Earth Sciences has welcomed over 140 high school students since 2004 into research positions on the topic of evolution. This approach, though an enriching and engaging learning 
opportunity, does limit access: students living far away would not be able to participate or would have to travel, a full-time commitment for several weeks is required, and a limited number of applicants are accepted each year (see also Blackmore and Cousin 2003).

Specifically related to evolution outreach programs, past or existing programs are concentrated in the United States of America, where a motivation included in the development of these programs is often to tackle the rather daunting religious lobby's influence on high school curriculum (i.e. Branch and Scott 2007; Robbins and Roy 2007; Cole 2006; Scharmann 2005; Carter and Wiles 2014; Horwitz et al. 2013), or even to increase 'acceptance of evolution' at the college level (i.e. Abraham et al. 2012) . This phenomenon is not prevalent on an international scale and we focus exclusively on the use of outreach as a means of effectively teaching students about evolution; a topic rarely addressed in science outreach programs, especially within Canada.

In the Ontario grade 11 biology curriculum, the learning of natural selection is described as: "investigate, through a case study or computer simulation, the processes of natural selection and artificial selection (e.g., selective breeding, antibiotic resistance in microorganisms), and analyse the different mechanisms by which they occur". Though small studies often show very little effect of simulation gaming on cognitive gains (but see Perry et al. 2008, Abraham et al. 2009) versus traditional teaching approaches (i.e. lectures), meta-analyses of adequately controlled studies do show that there is significant benefit to these active learning strategies (i.e. Vogel et al. 2006; Randel et al. 1992). In addition, active engagement in research related to the topic of study has been shown to further increase student interest in pursuing post-secondary studies in that field (reviewed by Kimbrough 1995). An outreach program by Campos \& Sá-pinto (2013) designed to teach elementary school students about the fundamental concepts of evolution, used a series of simulations, drawing activities and group discussions. Though no metrics of learning were assessed, the authors described the students as engaged and able to perform the tasks asked of them.

Here we describe an outreach program that can easily engage students across large geographic regions, requires minimal time commitment by students, is low cost, will actively engage students in simulation-based learning and scientific inquiry, and may benefit research in evolution by creating a mechanism for attaining large data sets through citizen science.

\section{The lesson plan and implementation Methods, approvals and consent}

This pilot project was conducted with the Upper Grand District School Board, in Ontario, Canada. Research
Proposal Approval for application FALL 2013-03 was received prior to entering the schools and all guardians of the participants signed an informed consent form to allow their child to participate and to allow us to collect anonymised information for publication.

The Upper Grand District School Board contains 11 High Schools and 64 elementary schools with approximate 64,000 students in the city of Guelph and Wellington and Dufferin Counties, Ontario, Canada. The Dandelion Outreach Program was presented to the Heads of Science from each High School from which 6 (9 SBI3U level classes) decided to participate in our pilot study.

In Ontario, the grade 11 biology-university preparation (SBI3U) course contains the following units: Diversity of Living Things, Evolution, Genetic Processes, Animals: Structure and Function, Plants: Anatomy, Growth, and Function. We designed our outreach program to touch on all but the animal biology unit. The curriculum focuses on learning about natural selection (specifically with the 'organism' as the unit of selection) by developing scientific inquiry skills beginning with initiation and planning through to communicating the results.

The lesson plan was built in collaboration between the researchers of the University of Guelph and a curriculum lead for the Upper Grand District School Board who met regularly to ensure that the lesson was well-integrated into the grade 11 curriculum.

\section{Lesson objectives}

The goals of the lesson were to 1) identify and fill in any knowledge gaps in the students' understanding of natural selection, 2) allow students to develop their own predictions regarding the effects of selection on a plant population, and 3) involve students in ongoing evolution research. In all but one grade 11 class that participated in our study, the students had very recently been introduced to the concept of natural selection and their biology teachers felt that a simulation activity would help them to understand the mechanisms and relevant 'units' of selection. Because we were unable to design a study with a control group of student (e.g. a group of students that were not first engaged in the natural selection simulation, or the dandelion evolution study), we developed a pre-assessment activity to identify the students' level of understanding of the mechanisms of natural selection and a post-assessment activity designed to test whether students had increased their understanding having completed our simulation and dandelion evolution study discussions.

\section{Pre-assessment}

We asked the students to write down all the words that come to mind when they think of the term 'natural selection'. We gave them a few minutes to work individually 
and then asked them to share their words with their neighbour. We asked for volunteers to share their group's words (Figure 1) (see Results for a sample list). These words and phrases allowed the instructors to quickly determine the level of understanding of the subject matter and to tailor learning to meet the needs of the students.

We found that most students wrote down words associated with 1) the four principles of natural selection, including 'survival of the fittest', 'variation', 'reproduction', and 'inheritance', 2) the result of natural selection, including 'change', 'evolution', 'descent with modification', and 3) beneficial selection, including 'adaptation' and 'advancement'. 'Darwin' was listed in all but one class, followed by 'Lamarck' and then 'Wallace'. With the words posted on the board for all the class to see, we focused their attention on words associated with 'variation' or 'difference' (i.e. survival of the fittest). We noticed that students were placing the unit of selection at the species level so we then asked them to consider whether survival of the fittest could happen within a species.

\section{The lesson}

Based upon the 'Spork and Beans' lesson developed by Burton and Dobson (2009), we told the story of our recent discovery of a new species in a local forest called Utensilus plasticus (a plastic spoon). We elaborated on the natural history of the species (largely to increase interest) and stressed the following observations:

Next, we told the students about the limitations of the environment:

1) the species feeds only on marshmallows,

2) the maximum population size is (coincidentally!) exactly the same size as the number of students in the class (approximately 28),

3) in order to reproduce each Utensilus plasticus must consume 10 marshmallows,

4) each Utensilus plasticus can produce one offspring without interacting with another individual.

A limited number of nesting sites meant that only the first 10 Utensilus plasticus individuals (should be adjusted for class size) to collect 10 marshmallows would reproduce.

The final list of rules (to slow the speed of the game so that it could be monitored by instructors) were shared with the students:

1) only the utensil can collect marshmallows

2) only one marshmallow can be 'consumed' by the utensil (i.e. placed in a plastic cup) at a time

3) one hand must remain holding the cup at all times

4) the bottom of the cup must remain on the floor.
The instructors then told the students that after the simulation, they would be asking the following question: Has the population of Utensilus plasticus evolved?

Students were asked to pick up identical spoons and cups (one of each per student) and to join the instructors out 'in the forest' (the hallway where a large rectangle was mapped out on the floor with masking tape). Once the rules were reviewed and everyone agreed on the starting population size of Utensilus plasticus spoons, the students were told that once they had successfully collected 10 marshmallows, they should stand up. A signal was sounded to indicate that they should begin their hunt for marshmallows and to collect them in the plastic cup (Figure 2). Once 10 students were on their feet (approx. 2 minutes), the round was ended. All standing students were asked to hold out their Utensilus plasticus in front of them. The entire group was asked to remember how many spoons had begun the game, and then to count how many had finished. We then allowed the surviving individuals to 'reproduce', effectively doubling the population size post-simulation. Then the students were asked: has this population evolved? Here the answer is 'no'; there was no evolution because there was no change in the composition of the population. In most classes, students first answered 'yes' to the question but the instructors allowed them moments to think about their response. After only a few seconds, students then demonstrated confusion and a few students in each class began exploring the possibility of a 'no' answer. The instructors then picked up on that and asked questions such as 'what would we see if there was evolution?' In fact there could be no evolution because there was no variation in the population to begin with all utensils were spoons. The lack of change can be

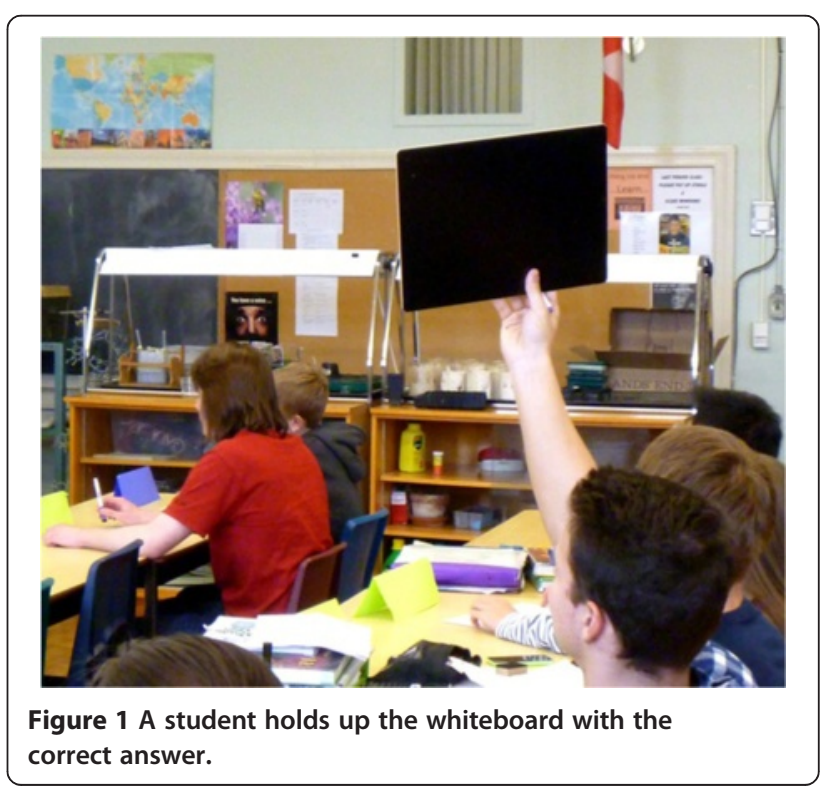




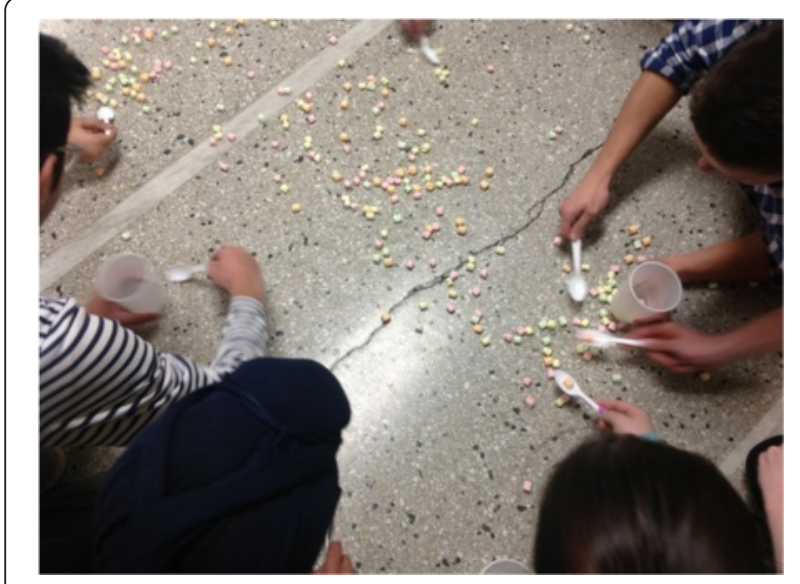

Figure 2 Students play the Natural Selection marshmallow simulation game.

contrasted against the change in the population size; in many cases and depending upon the number of students in the class, the population size is reduced but there is no change in the population's composition (no evolution).

We returned to the class and the simulation and results were reviewed. Then the instructors introduced an update in the story: after 15 generations of reproduction, a mutation had been found in the population of Utensilus plasticus: the fork! But this was a very rare mutation, found only in 4-6 (depending upon class size) individuals within the entire population. Students were asked to make predictions about what the outcome of another round would be. In all cases, students predicted that the forks would increase in frequency within the population.

In our implementation of this simulation it became clear that the forks are not beneficial (because it is difficult to remove the marshmallows from the tines of the fork and it ends up in a sticky mess), and used this as an opportunity to teach about non-adaptive traits (in the 7 of 9 classes where forks were initially selected against).

If, during the simulation where forks were introduced, they were first eliminated from the population, a third round was played in which the instructors introduced a change in the environment: students with forks were able to use their fingers to remove the marshmallows from the tines. This made the trait adaptive and, in all cases, the frequency of forks in the surviving reproducers increased. The instructors reviewed the numbers with the students and then asked again: has the population evolved?

By the end of the simulation, all students were able to identify correctly when 'evolution' had taken place and were able to describe the reasons that lead to their conclusion.
The experiment: does mowing affect dandelion evolution?

Upon returning to the classroom and cleaning up the marshmallows, students were told that we were going to 'switch gears' for a moment but that we would connect everything together soon. They were asked to answer the following question: what makes a good sports field? They were given a few minutes to work on their own and then instructed to share their answers with neighbouring students (Figure 3). We collected a sample of these answers and wrote them down on the board at the front of the class. These answers were divided into two, unlabelled columns, but which represented abiotic and biotic attributes. As an exercise, the students were asked to think of two appropriate column headings that could be used to classify the two columns. Several possible column headings were suggested by the students including: alive and dead, necessary and unnecessary. If the words 'abiotic' and 'biotic' were not suggested (approximately half of the time), the instructors wrote the first letters of each term above the column and within a minute, the correct answers were always given.

Focusing the students' attention to words like 'mowing', 'maintenance', 'grass' or 'no weeds', the instructors then asked: If mowing time frames differ among schools, do you think that there will be a difference in the plants? Here we allowed them time to converse with their neighbours before sharing some of their discussion.

\section{Post-assessment}

In order to determine whether the lesson and activities had been of value in teaching about some of the ways in

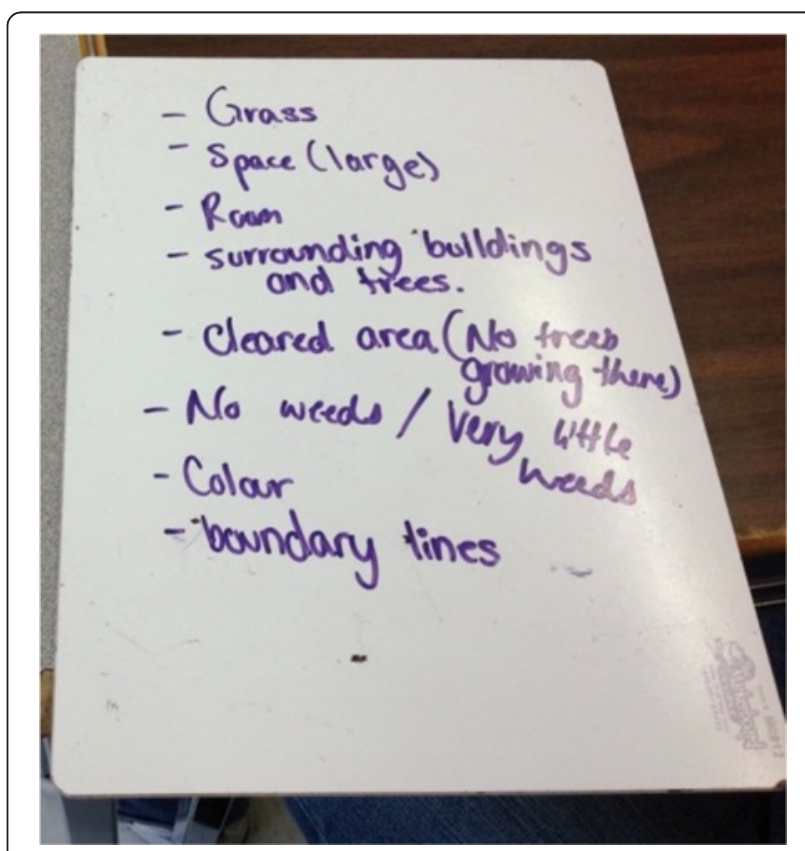

Figure 3 What makes a good sports field? 
which natural selection might work, we asked the students to make specific predictions about what they think would happen to the dandelions in the fields around their schools if the mowing frequency varied. Plausible predictions related to the principles of natural selection indicated the value of the activity, whereas implausible or unrelated predictions suggested that students remained unclear about natural selection. In all classes, we found that most students gave predictions related to the survival of individuals within a species best suited for the conditions. Some predictions were made at the 'species' level and some predictions were not related to natural selection principles.

We then introduced the dandelion experiment. An instructor told the students that the previous question was exactly what the researchers at the University of Guelph were wondering and that there really wasn't an answer yet. The goal of this study is to test whether natural selection imposed by mowing has resulted in genetically based differences in dandelion growth patterns between school fields that experience different mowing scheduled. Data will be collected by students in their school fields and seeds will collected and sent to the University of Guelph where they will be grown under common greenhouse conditions. Consistent differences in stem height between plants grown in the greenhouse from seeds from different schools would indicate that differences in stem height between schools are genetically based (i.e. have evolved) and are not simply due to environmental differences between school yards. The students were asked if they wanted to help figure out the answer to this question. We told the students that five other high schools were participating and that each of them should keep track of how often their school yard was being mowed. A complete description of the sampling protocol was then shared with the students and the sampling packages were left with their respective teachers. The entire lesson was accomplished in a 70 minute time block during one class period.

\section{The materials and methods of the experiment}

In each sampling kit, the following items were provided (see Figure 4):

1) Sampling instructions for the biology teacher with an option to sample only once or multiple times

2) Instructions card (see Figure 5) printed on cardstock to bring into the field while sampling

3) 30 sampling data sheets (see Figure 6) with sampling instructions on reverse side

4) 10 seed collection envelopes with data labels for students to indicate their group name, school, and collection date

5) 10 rulers for measuring dandelion stems

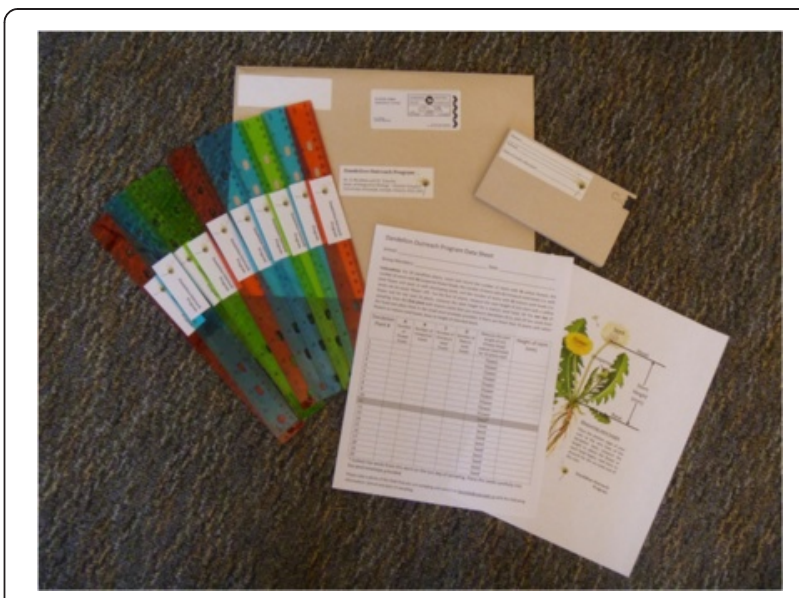

Figure 4 Dandelion Outreach Program lesson materials.

6) 50 popsicle sticks for students to mark out their sampling quadrat

7) 1 large self-addressed pre-paid envelope for seeds and data sheets to be returned to research lab

The total cost of this kit was approximately CDN $\$ 13.00$.

We concluded the class period by inviting the students to visit the Phytotron at the University of Guelph at some point in the future where their dandelions would be grown in the greenhouses under controlled conditions to see if any differences in stem height that they measured persisted into second and third generation dandelions under common greenhouse conditions. This is a technique that evolutionary biologists use to determine whether differences between plants growing in different places are due to their local environment or their underlying genetics.

\section{Observations and reflections}

Though all of us as educators seek out opportunities to engage students in experiential learning opportunities and activities, we were initially concerned that the lesson plan would not yield the connectors and segues necessary to jump from topic to topic. However, we were pleased to observe that the students were eager to contribute, and that their creativity and knowledge of biology were sufficient to fully engage with the program. We were particularly impressed with the effectiveness of the lesson to get students to contribute reasonable predictions regarding how mowing frequency might affect plant evolution. Though we could not have a real control group of students given the limitation of working within the secondary school systems, teachers reported that the lesson contributed to students' understanding of the principles of natural selection and primed the students for thinking about how human activities might affect the species around us. 


\section{Instructions:}

1) Locate your sampling area using a random sampling technique.

2) Using your ruler, measure out a $120 \mathrm{~cm} \times 120 \mathrm{~cm}$ square area and have members of the group mark each corner temporary (you can use four pencils, or sticks, or any other object).

3) Count the number of individual dandelion plants (see diagram below for an image of 1 individual plant) and record that number on the Data sheet.

4) For all 20 dandelion plants, count and record the number of stems with A) yellow flowers, the number of stems with B) unopened flower heads, the number of stems with C) immature seed heads (i.e. with both flower and seed, or with developing seed, or fluff), and the number of stems with D) mature seed heads (i.e. seeds can be easily 'blown' off).

5) For the first 10 plants, measure the stem height of one stem with a yellow flower and for the next 10 plants, measure the stem height of one stem with a mature seed head.

6) On the seed collection day of sampling, from the first plant with mature seeds that you measure (dandelion \#11), pick off the seeds from the head and place them in the small seed envelope provided.

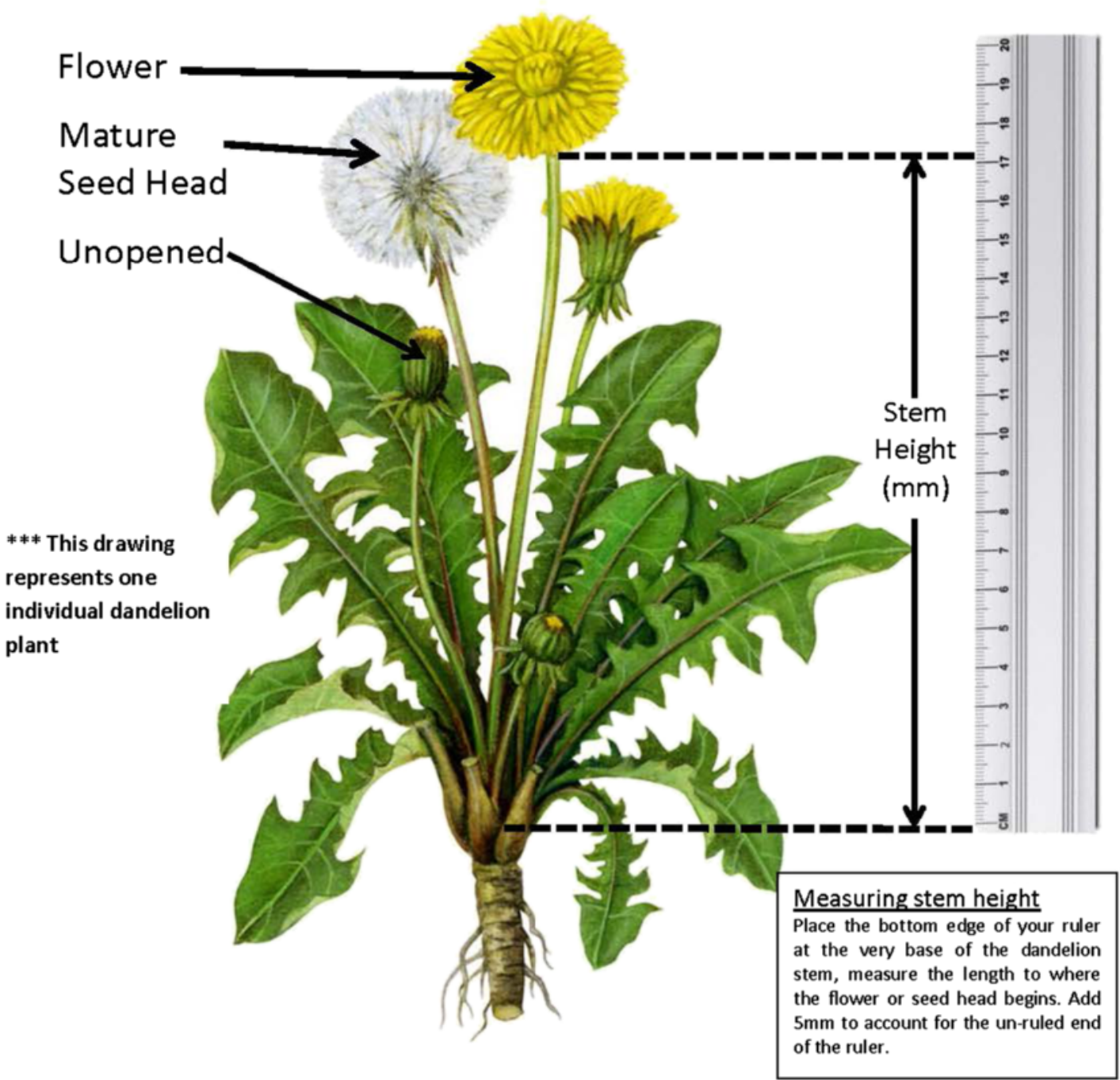

Figure 5 Dandelion Outreach Program student instructions for inquiry-based activity. 


\section{Dandelion Outreach Program Data Sheet}

School: Date:

Group Members:

Number of separate dandelion plants in a $120 \mathrm{~cm} \times 120 \mathrm{~cm}$ area:

\begin{tabular}{|c|c|c|c|c|c|c|}
\hline $\begin{array}{c}\text { Dandelion } \\
\text { Plant \# }\end{array}$ & $\begin{array}{c}\text { A } \\
\text { Number } \\
\text { of } \\
\text { Flower } \\
\text { heads } \\
\end{array}$ & $\begin{array}{c}\text { B } \\
\text { Number of } \\
\text { Unopened } \\
\text { heads }\end{array}$ & \begin{tabular}{|c} 
C \\
Number of \\
Immature \\
seed \\
heads
\end{tabular} & $\begin{array}{c}\text { D } \\
\text { Number of } \\
\text { Mature } \\
\text { seed } \\
\text { heads } \\
\end{array}$ & $\begin{array}{l}\text { Measure the stem } \\
\text { length of one } \\
\text { (Flower head/ } \\
\text { mature seed head) } \\
\text { for } 10 \text { plants each }\end{array}$ & $\begin{array}{l}\text { Height of stem } \\
(\mathrm{cm}) \\
\text { e.g. } 7.2 \mathrm{~cm}\end{array}$ \\
\hline 1 & & & & & Flower & \\
\hline 2 & & & & & Flower & \\
\hline 3 & & & & & Flower & \\
\hline 4 & & & & & Flower & \\
\hline 5 & & & & & Flower & \\
\hline 6 & & & & & Flower & \\
\hline 7 & & & & & Flower & \\
\hline 8 & & & & & Flower & \\
\hline 9 & & & & & Flower & \\
\hline 10 & & & & & Flower & \\
\hline 11 & & & & & Seed* & \\
\hline 12 & & & & & Seed & \\
\hline 13 & & & & & Seed & \\
\hline 14 & & & & & Seed & \\
\hline 15 & & & & & Seed & \\
\hline 16 & & & & & Seed & \\
\hline 17 & & & & & Seed & \\
\hline 18 & & & & & Seed & \\
\hline 19 & & & & & Seed & \\
\hline 20 & & & & & Seed & \\
\hline
\end{tabular}

* Collect the seeds from this stem on the last day of sampling. Place the seeds carefully into the seed envelope provided.

If you would like, please take a photo of the field that you are sampling and send it to: biomlab@uoguelph.ca with the following information: School and date of sampling.

Figure 6 Dandelion Outreach Program student data collection sheet.

In order to assess the level of understanding related to natural selection by the students in each class, we collected lists of the responses to our question "what comes to mind when we say 'natural selection'?" (Table 1). This exercise was performed by all but one class. In this one class the students had not yet covered their natural selection unit in their regular biology class. Nevertheless, the students from this class were able to achieve the same outcomes as all others in subsequent activities.

In most cases, the differential success of species was identified by students, but there was never mention of differential survival within populations. Therefore, the need for 'variation' was not frequently included in the initial lists developed by students to our initial question. Instructors then focussed on exploring the importance of variation within populations and emphasizing it during the marshmallow simulation.

\section{Has the population evolved?}

Simulation 1: In most cases, students immediately answered 'yes, the population has evolved' and some had concerned or confused expressions. When the students that responded 'yes' were asked to elaborate they became stuck on an explanation and quickly changed their answer to 'no, because nothing has really changed'. Sometimes they added 'except for population size'. In a couple of instances, the explanation for 'yes' was that we had selected for the fastest Utensilus plasticus individuals. These students were praised for their contribution and then we re-calibrated the question to ask whether the physical attributes of Utensilus plasticus had evolved. All students agreed that the answer was no. In two classes, students answered the question immediately with: there is no evolution because there were no mutations! 
Table 1 Responses of grade 11 students to the question "what comes to mind when we say 'natural selection'?"

\begin{tabular}{|c|c|c|}
\hline People & $\begin{array}{l}\text { Aristotle } \\
\text { Darwin } \\
\text { Lamarck }\end{array}$ & $\begin{array}{l}\text { Malthus } \\
\text { Plato } \\
\text { Spencer } \\
\text { Wedgewood }\end{array}$ \\
\hline oncepts & $\begin{array}{l}\text { Adaptability } \\
\text { Adaptations } \\
\text { Adapt to Environment } \\
\text { Advancement } \\
\text { Alleles } \\
\text { Analogous Structures } \\
\text { Antibiotic resistance } \\
\text { Artificial Selection } \\
\text { Benefit } \\
\text { Biology } \\
\text { Bottleneck effect } \\
\text { Chance } \\
\text { Change } \\
\text { Circle of life } \\
\text { Competition } \\
\text { Continuation of species } \\
\text { Decreased diversity } \\
\text { Descent with Modification } \\
\text { Dinosaurs } \\
\text { Ecosystem } \\
\text { Environment } \\
\text { Environment favours a trait } \\
\text { Favourable genes } \\
\text { Fluctuations in environment }\end{array}$ & $\begin{array}{l}\text { Fluctuations in organisms } \\
\text { Frequency } \\
\text { Generations } \\
\text { Genes } \\
\text { Genetic drift } \\
\text { Genotype and Phenotype } \\
\text { Heritage } \\
\text { Inheritance } \\
\text { Lethal, non-lethal, beneficial } \\
\text { Living organisms } \\
\text { Mutations } \\
\text { Population decay or growth } \\
\text { Religion } \\
\text { Reproduction } \\
\text { Species } \\
\text { Species change } \\
\text { Suitability } \\
\text { Surroundings } \\
\text { Survival } \\
\text { Survival of the fittest } \\
\text { Traits } \\
\text { Transmutation } \\
\text { Variation } \\
\text { Weaker ones die off }\end{array}$ \\
\hline Places & Galapagos Tierra del Fuego & \\
\hline Organisms & Finches Pepper Moths & \\
\hline Misc. & Beagle voyage & \\
\hline
\end{tabular}

\section{What would you predict about the fork mutation?}

In all cases, the first prediction was that the forks would be better able to catch marshmallows and that, therefore, there would be a greater proportion of forks in the 10 reproducing individuals than prior to running the simulation.

Students were generally surprised to see that their prediction about the frequency of forks was not supported. Some of them believed that their predictions were 'wrong'. This was clarified by explaining the distinction between an incorrect prediction (e.g. a statement that does not predict the direction of change of a measured variable) versus one that, when tested, is not supported by the data.

\section{What makes a good sports field?}

In all classes, students largely focused on abiotic factors (including concession stands!) but all of them identified at least a few biotic factors. Those factors that allowed for a fluid transition to introducing the next question were: maintenance, regular mowing, no weeds, only grass (Table 2). At least two of these were identified by each class. Most classes were familiar with the terms abiotic and biotic but, more importantly, the students were able to recognise the sorting of the columns into living and non-living factors. Other suggestions included: required vs. extra, independent vs. dependent, natural vs. non-natural.

\section{If mowing time frames differ among schools, do you think} that there will be a difference in the plants?

Here the predictions given by students can be classified within three categories: 1) Natural selection within a species, 2) Natural selection among species, 3) Genetic drift. Most of the predictions fell within the first category: students made predictions about how individual plant species might be affected over time (Table 3). Some students predicted that some species would outcompete others, and fewer students suggested that mowing may represent a bottleneck effect by dramatically reducing the population size. Predictions falling into the second and third categories were not anticipated by the instructors.

All of the students and their teachers expressed interest in participating in the study to answer the question: does mowing frequency affect the stem height of dandelions? To achieve this, students will spend time on the grassy fields around the school collecting data on the density of dandelion plants and the stem heights of both plants with

Table 2 Responses of grade 11 students to the question "what makes a good sports field?"

\begin{tabular}{ll}
\hline Abiotic & Biotic \\
\hline Adapts to weather & $\begin{array}{l}\text { Grass } \\
\text { (real grass) } \\
\text { Bathrooms }\end{array}$ \\
Bleachers/stands & Only grass \\
Clean (no garbage) & No competition with \\
Climate & Other species \\
Concession stands & No species diversity \\
Compact/soft terrain & No pests \\
Colour & No trees \\
Drainage & No weeds or dandelions \\
Even/Flat ground & Seeding \\
Fertiliser & \\
Free access & \\
Good weather & \\
Level & \\
Lights & \\
Lines and boundaries & \\
Location & \\
Maintenance/grooming & \\
Mowed (regularly) & \\
Multi-purpose & \\
Nets/Equipment No holes & \\
No obstacles & \\
No rocks & \\
Not gross & \\
Nutrients & \\
Shade & \\
Soil & \\
Spacious/Size & \\
Sun & \\
Stable environment & \\
Turf & \\
Water & \\
Water-balanced & \\
\hline
\end{tabular}


Table 3 Predictions devised by grade 11 students when asked "if mowing time frames differ among schools, do you think that there will be a difference in the plants?" Predictions in bold represent those that were not directly related to the principles of natural selection

\begin{tabular}{ll}
\hline & Mowing Frequency \\
Increased & Decreased \\
\hline Faster growth & $\begin{array}{l}\text { Lower population } \\
\text { Higher population } \\
\text { Faster life cycle }\end{array}$ \\
Lower population & Taller stems \\
Higher population & \\
Shorter stems & \\
Lower reproduction & \\
Higher reproduction & \\
More dispersion & \\
More seeds & \\
Higher density & \\
Lower survival & \\
Thicker and stronger stems & \\
Selection for a medium height & \\
Stronger and deeper roots & \\
Change in colour & \\
Change in pollinator & \\
Change in dispersion & \\
\hline
\end{tabular}

flowers and with mature seed heads. Although the density of dandelions is not central to this lesson these data provide the opportunity to subsequently examine effects of selection caused by intraspecific competition. Students will also collect the seeds from approximately 10 dandelions per field. For this pilot study, University of Guelph researchers will compile and analyse the data though in the future data collected in previous years will be made available to teachers and students so that they might be further incorporated into their classroom activities. Over the summer months, the seeds will be planted in the greenhouse and the second and third generation dandelion plants will be measured to remove the possibility of phenotypic plasticity. (The instructors were pleased to note that several students questioned the effect of other local conditions on the dandelions and wondered about how we might account for this).

\section{Discussion}

In an educational setting where students are able to access massive amounts of content, the role of the teacher and the needs of the student have changed considerably. Our attention must now be directed towards critical thinking, inquiry-based and problem-based learning to teach and help students develop the skills necessary for success after graduation. Engaging students in inquirybased active learning in evolution can present specific challenges and the Dandelion Outreach Program may help to address this challenge.

Active learning and inquiry-based learning have been shown to be effective means of teaching, resulting in students demonstrating a deeper approach to learning (e.g. Biggs 2003; Robbins and Roy 2007) that lead to higher performance on assessments (e.g. Eddy et al. 2013) and advanced intellectual development (e.g. Blackmore and Cousin 2003) if properly balanced with deliberate learning outcomes. Generally, the use of simulation in active learning curriculum can yield positive results though smaller studies often fail to demonstrate them (Vogel et al. 2006). In addition, the use of simulations alone may not be as effective for all students (i.e. males vs. females; Vogel et al. 2006). A mixed approach to active, inquiry-based learning is, therefore, likely to yield a positive outcome to learning in more students. Our lesson plan was structured into three parts, the first two being active learning, with students participating in a studentcentered approach to learning about natural selection and designing predictions for a future study, followed by inquiry-based learning where students were responsible for collecting their own data to answer a relevant research question.

Edelson et al. (1999) identified five key challenges to introducing inquiry-based learning opportunities into curriculum. They are: 1) student motivation, 2) accessibility of investigation techniques, 3) student background knowledge, 4) management of extended activities, and 5) the practical constraints of the learning environment. Students were easily motivated to participate because the investigators made on-site visits to the classrooms, thus breaking up the routine of traditional instruction. If our program expands to schools where we will not be able to participate in the lesson and presentation of the program to individual classes we will need to explore other means of overcoming this challenge. To ensure that students found the activities accessible, we began by paring down the original 'Spork and Beans' lesson developed by Burton and Dobson (2009) to the essential components that addressed our learning outcomes. For the inquiry-based portion of the program, we selected a species that is familiar to all students placed within a familiar context (the sports field). Finally, we developed a sampling protocol that is simple to execute. Though this was only tested on one class, we found that even if the students had not covered the evolution portion of the curriculum, we were able to provide the key background information to allow students to participate in the program and to make plausible predictions related to the effects of mowing frequency. We introduced some flexibility in the sampling protocol to allow teachers to choose whether they participated in the extended protocol, or the single sampling protocol. This gave teachers the ability to select the degree to which they wanted students to engage in either a 'more authentic' demonstration of scientific inquiry or to simply give their students a 'taste'. This addressed both challenges 4 and 5: teachers know their students best, can more readily assess their ability to manage extended activities and can make 
decisions in the interest of their students' learning based upon their learning context.

The Dandelion Outreach Program was received with enthusiasm by the Upper Grand District School Board administration, the heads of science from each school, and by the biology teachers involved. We found that the grade 11 students had sufficient background knowledge of evolution and natural selection to actively engage in our lesson plan. The Utensilus plasticus simulation game was enjoyed by the student participants and it was relevant to helping them answer post-assessment questions such as: Did the population evolve? And what could we predict about the effect of mowing on plant populations? We found that the majority of students made plausible predictions about the effects of mowing on plant evolution from a natural selection perspective.

The Program and the sampling method were designed to allow for maximum flexibility in scale. Costs were kept to a minimum (approximately CDN\$ 13.00 per class of 30 students) to ensure maximum accessibility. The lesson plan took approximately 70 minutes to execute, including the engagement exercises. The sampling protocol required a minimum of 1 hour outdoors. Some teachers opted for the extended sampling protocol to provide students with a more authentic scientific research experience. This Program could continue to be run at this small scale, with supplemental instruction provided by university biologists, but it is also possible to extend it to all the schools in the province of Ontario. We will be developing a formal lesson plan with additional supporting materials for biology teachers that will be fully integrated into the grade 11 evolution curriculum unit. This will allow us to quantitatively assess the effectiveness of this program on learning by students and, additionally, it will allow us to use the data collected to address, on a large scale, the evolutionary effect of mowing on dandelions. We will develop meaningful ways of following up with participating students, including on-site visits in the final weeks of grade 11 to visit the dandelions growing from the previous year, or for grade 12 students to visit the dandelions that they collected in grade 11 while they are covering the genetics unit of the curriculum. We will also develop an interactive website to allow students to upload data, generate results tables and charts, send us questions, and watch video tours of our growing operations.

An evolution readiness program developed for fourth graders in Massachusetts, Missouri, and Texas, U.S.A. tracked the implementation and success in addition to the challenges faced over three years (Horwitz et al. 2013). The most significant challenge was that of maintaining the sustainability of the program because of a changeover of personnel in the schools, at both the administrative and the teaching levels. This is likely to be our biggest challenge over the next few years as we expand the program beyond the local school board. For this reason, we will be testing the validity of our program to ensure sound learning outcomes and propose that it be introduced into our provincial curriculum. This would address challenges of program sustainability.

\section{Competing Interests}

The authors declare that they have no competing interests.

\section{Authors' contributions}

SJ participated in designing the program and curriculum and the delivery, analysed the outcomes and wrote the manuscript. SB participated in designing the curriculum and the delivery. AM conceived of and participated in designing the program and provided a critical revision of the manuscript.

\section{Acknowledgements}

The authors are grateful to the Rene van Acker for comments on the program design and to all the teachers, heads of science departments, principals, and students of the schools participating in the project.

\section{Author details}

${ }^{1}$ Department of Integrative Biology, University of Guelph, N1G 2 W1 Guelph, ON, Canada. ${ }^{2}$ Upper Grand District School Board, 500 Victoria Rd N, N1E 6 K2 Guelph, ON, Canada.

Received: 3 August 2014 Accepted: 8 January 2015

Published online: 05 February 2015

\section{References}

Abraham, J. K., Meir, E., Perry, J., Herron, J. C., Maruca, S., \& Stal, D. (2009). Addressing undergraduate student misconceptions about natural selection with an interactive simulated laboratory. Evolution: education and outreach, 2(3), 393-404. doi:10.1007/s12052-009-0142-3.

Abraham, J. K., Perez, K. E., Downey, N., Herron, J. C., \& Meir, E. (2012). Short lesson plan associated with increased acceptance of evolutionary theory and potential change in three alternate conceptions of macroevolution in undergraduate students. CBE Life Sciences Education, 11(2), 152-164. doi:10.1187/cbe.11-08-0079.

Bell, R., Blair, M., Crawford, B., \& Lederman, N. (2003). Just do it? Impact of a science apprenticeship program on high school students' understanding of the nature of science and scientific inquiry. Journal of Research in Science Teaching, 40, 487-509.

Biggs, J. (2003) Teaching for Quality Learning at University: What the Student Does. 2nd edn. Buckingham: SRHE and Open University Press.

Blackmore, P., \& Cousin, G. (2003). Linking teaching and research through research-based learning. Educational developments, 4(4), 23-27.

Branch, G., \& Scott, E. C. (2007). Overcoming obstacles to evolution education: in the beginning. Evolution: education and outreach, 1(1), 53-55. doi:10.1007/ s12052-007-0012-9.

Burton, S. R., \& Dobson, C. (2009). Spork \& beans: addressing evolutionary misconceptions. The American Biology Teacher, 71(2), 89-91. doi:10.1662/ 005.071.0208.

Campos, R, \& Sá-pinto, A. (2013). Early evolution of evolutionary thinking: teaching biological evolution in elementary schools, 6(1), 1. doi:10.1186/ 19366434-6-25

Carter, B. E., \& Wiles, J. R. (2014). Scientific consensus and social controversy: exploring relationships between students' conceptions of the nature of science, biological evolution, and global climate change. Evolution: education and outreach, 7(1), 6. doi:10.1186/s12052-014-0006-3.

Cole, E. (2006). Creation: a Webquest for evolutionary biology. Life Sciences - HHMI Outreach, (Part 1). http://outreach.mcb.harvard.edu/teachers/Summer06/ EricaCole/webquest_creation.pdf.

Eddy, S. L., Crowe, A. J., Wenderoth, M., \& Freeman, S. (2013). How should we teach tree-thinking? An experimental test of two hypotheses. Evolution: education and outreach, 6(1), 13. doi:10.1186/1936-6434-6-13.

Edelson, D. C., Gordin, D. N., \& Pea, R. D. (1999). Addressing the challenges of inquiry-based learning through technology and curriculum design. The journal of learning sciences, 8(3), 391-450. 
Gibson, H., \& Chase, C. (2002). Longitudinal impact of an inquiry-based science program on middle school students' attitudes toward science. Science Education, 86, 693-705.

Healey, M. (2005). Linking research and teaching: exploring disciplinary spaces and the role of inquiry-based learning. In R. Barnett (Ed.), Reshaping the University: new relationships between research, scholarship, and teaching (pp. 67-78). McGraw Hill/Open University Press: New York.

Helm, E., Parker, J., \& Russell, M. (1999). Education and career paths of LSU's summer science program students from 1985 to 1997. Academic Medicine, 74, 336-337.

Horwitz, P, McIntyre, CA, Lord, TL., O'Dwyer, LM., \& Staudt, C. (2013). Teaching "Evolution readiness" to fourth graders. Evolution: Education and Outreach, 6(1), 21. doi:10.1186/1936-6434-6-21.

Kimbrough, D. (1995). Project design factors that affect student perceptions of success of a science research project. Journal of Research in Science Teaching, 32, 157-175.

Louie, H, Srivastava, A. (2011). Resources for Pre-University Power Engineering Outreach, IEEE PES General Meeting, Detroit, Ml, 24-29th July, 2011.

Markowitz, D. G. (2004). Evaluation of the long-term impact of a university high school summer science program on students' interest and perceived abilities in science. Journal of Science Education and Technology, 13(3), 395-407. doi:10.1023/B:JOST.0000045467.67907.7b.

McKendall, S., Simoyi, P., Chester, A., \& Rye, J. (2000). The health sciences and technology academy: utilizing pre-college enrichment programming to minimize post-seondary education barriers for underserved youth. Academic Medicine, 75, S121-S123.

Merton, D. A. (2011). Enhancing awareness of the diagnostic medical sonography professions. Journal of ultrasound medicine, 30, 1077-1084.

Ministry of Education. (2008). The Ontario Curriculum Grades 11 and 12 Science.

Perry, J., Meir, E., Herron, J. C., Maruca, S., \& Stal, D. (2008). Evaluating two approaches to helping college students understand evolutionary trees through diagramming tasks. CBE Life Sciences Education, 7(2), 193-201. doi:10.1187/cbe.07-01-0007.

Randel, J., Morris, B., Wetzel, C., \& Whitehill, B. (1992). The effectiveness of games for educational purposes: A review of recent research. Simulation \& Gaming, 23, 261-276.

Robbins, J. R., \& Roy, P. (2007). The natural selection. The American Biology Teacher, 69(8), 460-466.

Scharmann, L. C. (2005). A proactive strategy for teaching evolution. The American Biology Teacher, 67(1), 12-16.

Vogel, J. J., Vogel, D. S., Cannon-Bowers, J., Bowers, C. A., Muse, K., \& Wright, M. (2006). Computer gaming and interactive simulations for learning: a meta-analysis. Journal of Educational Computing Research, 34(3), 229-243. doi:10.2190/FLHV-K4WA-WPVQ-HOYM.

Waksman, B. (2003). The scientist as school teacher. Journal of Science Education and Technology, 12, 51-57

\section{Submit your manuscript to a SpringerOpen ${ }^{\circ}$ journal and benefit from:}

- Convenient online submission

- Rigorous peer review

- Immediate publication on acceptance

- Open access: articles freely available online

- High visibility within the field

- Retaining the copyright to your article

Submit your next manuscript at $>$ springeropen.com 